\section{A escrita no pensamento de Vilém Flusser}

Carmem PRATA ${ }^{1}$

Resumo: Este artigo tem a intenção de explorar o tema da escrita, destacando o ponto de vista do filósofo e teórico da mídia Vilém Flusser. A comunicação escrita é tomada como objeto para compreensão do homem e da sociedade, diante do processo de digitalização de conteúdos. Entende-se que percorrer o universo teórico das mídias é caminho obrigatório para pesquisadores do campo da comunicação, em tempos de produção, armazenamento, distribuição e consumo de conteúdos culturais realizados prioritariamente nos ambientes digitais. A partir daí, identifica-se em Flusser, e em alguns dos autores com os quais seu pensamento dialoga, uma tensão entre a materialidade e a produção de subjetividades.

Palavras-chave: 1. Comunicação escrita; 2. Livro e cultura letrada; 3. Livro e mídia

\section{A escritura y el pensamiento de Vilém Flusser}

Resumen: Este artículo pretende abordar el tema de la escritura, destacando el punto de vista del filósofo y teórico de los medios Vilém Flusser. La comunicación escrita se toma como objeto para la comprensión del hombre y la sociedad, ante del proceso de impresión digital de contenidos. Se entiende que conocer el universo teórico de los medios es paso obligado para los investigadores del campo de la comunicación en tiempos de producción, almacenamiento, distribución y consumo digitales. A partir de ahí, se identifica en Flusser, y algunos de los autores con los cuales se relaciona su pensamiento, una tensión entre la materialidad y la producción de subjetividad.

1 Mestranda do Programa de Pós-Graduação em Comunicação da Universidade do Estado do Rio de Janeiro (UERJ). É integrante do Laboratório de Pesquisas em Tecnologias de Comunicação, Cultura e Subjetividade (LETS), que reúne grupos de pesquisa, incluindo Livros e Cultura Letrada e Comunicação, sob a coordenação do prof. Dr. Márcio Souza Gonçalves. Possui MBA em Gestão de Bens Culturais, pela Fundação Getulio Vargas (FGV-SP, 2010). É graduada em Comunicação, com habilitação em Jornalismo, pela Faculdade de Comunicação Helio Alonso (FACHA, 1987). Hoje, como bolsista Proatec, colabora na Editora da Universidade do Estado do Rio de Janeiro, na Assessoria de Comunicação e Projetos. E-mail: cprata6@ gmail.com
Palabras clave: comunicación escrita; Libro e cultura letrada; 3. Libro e medios.

\section{Introdução}

O tema das Tecnologias de Informação e Comunicação (TIC) abre um leque de questões para o entendimento das produções culturais na atualidade. Vimos que as fronteiras entre produção, distribuição e consumo de conteúdos culturais foram rompidas com a convergência de diferentes mídias. Mudanças são percebidas na práxis das comunicações e da cultura, a exemplo do já clássico caso da música, no qual nem todo o aparato da indústria fonográfica interrompeu o processo de digitalização. Pelo contrário, incentivou novos modelos de distribuição, novos modos de produzir e de ouvir música.

Estreitando o olhar para a comunicação escrita, observamos que ela representou um salto no desenvolvimento das sociedades modernas. Se contraposta à tradição oral, teria permitido a fixação e a difusão do conhecimento, por meio da sistematização do pensamento, naquilo que hoje denomina-se como cultura letrada. Por seu uso em diferentes suportes, desde a Antiguidade: tábuas de argila, rolos de papiro ou pergaminhos, códices e, mais recentemente, livros e dispositivos eletrônicos, o tema da escrita está ligado, também, a esses artefatos.

O aperfeiçoamento da prensa e a tipografia permitiriam a reprodução de um número maior de textos, em menor tempo e a um custo menor, o que caracteriza a expansão da comunicação escrita a partir do século XV. Alguns estudiosos consideram que, embora os livros impressos circulem mais entre os mais privilegiados socialmente, ainda assim, circulam bem mais do que circulavam os códices. De forma que, "a invenção da tipografia representa sem sombra de dúvida uma verdadeira revolução democrática." (CARRIEÈRE e ECO, 2009, p. 106).

Recorremos a uma simplificação sobre as mudanças percebidas na forma escrita de comunicação, para oferecer uma noção do ritmo acelerado das inovações, especialmente verificada nos dias de hoje. Dispostas cronologicamente, dos primeiros sinais da escrita, identificados nas antigas civilizações, até os códices foram decorridos pouco mais de três mil anos; do códice aos tipos móveis, cerca de mil anos; dos tipos móveis à internet, 500 anos; da internet à web, 11 anos; da web ao algoritmo de relevância do Google, oito anos. (DARNTON, 2010).

$\mathrm{Na}$ busca por matizes que permitam avançar no universo da comunicação escrita, encontramos o pensamento do filósofo Vilém Flusser. A escrita é vista aqui como objeto de estudo para compreensão do homem 
e da sociedade. Entendemos que percorrer o universo teórico das mídias é um caminho imperativo para pesquisadores do campo da comunicação, em tempos de produção, armazenamento, distribuição e consumo de conteúdos culturais realizados prioritariamente nos ambientes digitais.

\section{A escrita por Vilém Flusser - um exercício de metaescrita}

O filósofo e teórico da mídia Vilém Flusser (1920-91) tem sua obra apresentada pelo historiador Mark Poster, no livro Into the Universe of Technical Images (2011), como crucial para o entendimento dos processos de interação entre o homem e a máquina. Flusser é destacado, entre os pensadores do século XX, por suas análises a cerca dessas inter-relações, fundamentando a construção do que o teórico chamou de "comunicologia" , uma teoria da comunicação ou uma ciência da mídia.

Vilém Flusser viveu no Brasil por mais de 30 anos (1940-72), onde lecionou na Universidade de São Paulo (USP) e na Fundação Armando Alvares Penteado (FAAP), nas disciplinas de filosofia e teoria da comunicação. Elementos da cultura, como imagem, áudio e texto, são vistos na obra desse autor tcheco, naturalizado brasileiro. Entretanto, seus estudos são relativamente desconhecidos pela maioria dos pesquisadores deste país, à exceção do título Filosofia da Caixa Preta - Ensaios para uma futura filosofia da fotografia (1985).

Ao deter-se sobre o tema da escrita, Flusser destaca uma outra função que não somente a de sistematizar o pensamento, mas de levar nossas ideias em direção ao outro, ao leitor-receptor. Escrever, então, torna-se um gesto não apenas reflexivo e interior, mas um gesto expressivo, voltado para o exterior e, portanto, uma prática comunicacional. Para esse autor, $\mathrm{h}$

á também um feedback entre a técnica e o homem ou uma consciência em transformação.

A escrita é vista pelo filósofo Vilém Flusser como uma arte, que articula e produz um estado da mente chamado de consciência histórica. Para ele, a história começa com a invenção da escrita, não apenas porque a escrita nos permite reconstituir o passado, mas porque o mundo só é percebido como um processo quando conceituado pelo texto escrito. De maneira que:

2 A "comunicologia" pode ser descrita como uma teoria da comunicação, desenvolvida por Flusser, a partir de um conjunto de análises das comunicações humanas e das suas estruturas. O termo "comunicologia" traduz o título do livro Kommunikologie , publicado em alemão em 1998.
A diferença entre a pré-história e a história não é posta pelos documentos escritos, que nos permitem ter conhecimento posterior ao fato, mas porque a história é construída por homens letrados que experimentam, entendem e avaliam o mundo em processo, considerando o pensamento sobre a existência, o que não seria possível na pré-história. ${ }^{3}$. (FLUSSER, 2002, p.63).

Assim, a escrita teria instituído o acontecimento. Antes dela, nada teria acontecido, as coisas apenas ocorreriam.

Tábuas de argila, canetas esferográficas, máquinas de escrever e processadores de textos são vistos como canais que conduzem o pensamento histórico-discursivo, (...) "das imagens para os conceitos, das cenas para os processos.”(FLUSSER, 2010, p.36-37).

\section{A escrita na Antiguidade - a imagem desdobra- da em linhas}

Examinando as cerâmicas da Mesopotâmia, Vilém Flusser observa que os símbolos da escrita cuneiforme procuravam interpretar a imagem que eles acompanhavam. Assim, a escrita em sua gênese vai "explicar", "recontar" e "dizer" a imagem; e "faz isso como se estivesse rompendo a superfície da imagem em linhas de um texto, tornando 'explícito' o que estava 'implícito"'. (FLUSSER. 2002, p.64).

Logo, para esse autor, o propósito original da escrita foi o de transcodificar códigos bidimensionais, de tal forma que a tradução das imagens em linhas implicou em uma mudança radical de sentido.

O olho que decifra uma imagem varre a superfície, estabelecendo relações reversíveis entre os elementos que compõem a imagem, ou seja, indo e voltando enquanto decifra a imagem. Essa reversibilidade das relações, essa pluralidade de movimentos e sentidos, que prevalece dentro da imagem, emprestam certas características àqueles que usam as imagens para compreender o mundo, aqueles que ‘imaginam’. (FLUSSER, 2002, p.64).

3 Todas as traduções apresentadas ao longo deste texto são livre tradução da autora. 
Essa condição de circularidade do pensamento é comparada à ideia nietzschiniana de tempo cíclico, do eterno retorno, "como o dia é seguido da noite e a noite é seguida do dia (...)". Já com a escrita, o olho seguiria em uma direção ordenada pelos elementos do texto. Assim, aqueles que usam os textos para compreender o mundo teriam desenvolvido uma perspectiva linear, onde o tempo flui de forma irreversível, onde cada dia difere do outro, tal como os elementos do texto são distintos entre si. Para o filósofo, esse é o mundo da ciência e da tecnologia, das religiões e da política, o mundo histórico. (FLUSSER, 2002, p.64-65).

Flusser passa a questionar porque a escrita foi inventada, porque há seis mil anos o mundo da imaginação foi substituído pelo mundo conceitual. Para ele, a resposta está na necessidade de explicar algumas imagens que, como mediações entre o homem e o mundo, para ele.rna amais as imagens, visto que as $\mathrm{m}$.,,’, permitem uma ação sobre o espaço ocupado. Por isso, teria sido preciso aprender a decifrar as imagens. Já que “(...) o imaginário que produz mapas não é o mesmo imaginário que produziu pinturas rupestres, explicar as imagens com a ajuda de textos pode ser útil”. (FLUSSER, 2002, p.65).

Ao considerar o uso da escrita "um desenvolvimento da pré-história ou uma versão daquilo que estava implícito nos mitos pré-históricos", Vilém Flusser ressalta que a escrita foi privilégio de uma pequena elite, enquanto a grande maioria continuava uma existência pré-histórica. Na percepção do autor, apenas com a invenção da prensa e durante a revolução industrial, a consciência histórica tornou-se acessível a uma burguesia em ascensão.

Além disso, teria sido apenas através do sistema de ensino público primário, da alfabetização, que a consciência histórica seria estabelecida nos países industrializados. Esse pensamento é entendido aqui como contraditório, já que reflete uma certa polaridade entre o determinismo tecnológico e outras construções sociais.

Com a invenção da fotografia, um novo tipo de imagem viria ameaçar a supremacia da escrita e, em consequência, do pensamento histórico, conceitual, como se estivéssemos nos aproximando de um novo tipo de idade mágica-mítica. Contudo:

Seria um erro supor que a vida em meio a cartazes, sinais de trânsito, programas de TV, revistas ilustradas e imagens cinematográficas viria a ser como a vida antes da invenção da escrita. (FLUSSER, 2002, p.67).

\section{A dimensão comunicacional dos gestos}

Para Vilém Flusser, a poesia concreta representou um esforço de dar à escrita duas dimensões, o que só seria possível com o uso da máquina de escrever, como expõe o filósofo em sua teoria dos gestos. A partir de então, Flusser passa a considerar a dimensão comunicacional dos gestos como primordial em relação às outras dimensões. Os gestos de escrever, tatear, falar, amar, fazer, brincar, ouvir música, filmar, pintar, fotografar, entre outros, são tratados como fenômenos de expressão da cultura humana.

Para o filósofo, a máquina de escrever é a materialização de toda uma dimensão da vida ocidental no século XX. Programada para produção de textos em linhas, com o apoio de elementos da escrita, como os símbolos do alfabeto grego, a máquina de escrever desliza da esquerda para direita, retornando quando chega ao fim da linha. Por isso, uma análise fenomenológica da máquina de escrever seria um método eficiente para o autoconhecimento.

Segundo Flusser, é um erro pensar que a máquina limita a liberdade dos gestos. Teclar em uma máquina tornaria mais evidente a liberdade de expressão, limitaria menos do que o gesto de escrever com uma caneta, não apenas porque escrevemos mais depressa quando em uma máquina, mas porque a máquina permitiria a transgressão do gesto de escrever, dando uma outra dimensão à escrita. (FLUSSER, 1994, p. 34).

Já na acepção da palavra, gesto é todo e qualquer o movimento do corpo, principalmente das mãos, braços e cabeça para exprimir ideias ou sentimentos. A escrita, considerada o gesto mais característico de manifestação do pensamento, é vista como um movimento simbólico que exprime a nossa forma de estar no mundo. Assim, para Flusser, a escrita não poderia ser sempre a mesma.

\section{Uma temporalidade das mídias - a escrita em xeque}

Voltado para as especificidades de cada tecnologia, Vilém Flusser fala da escrita a partir de um contexto de (des) uso de códigos ditos lineares, frente ao crescente uso de códigos considerados bidimensionais, como a fotografia, o cinema e a televisão, associando cada mídia a uma temporalidade e fluxo específicos.

Como vimos na abordagem do filósofo, provenientes de uma sociedade histórica, os textos escritos seriam decodificados de forma linear, em uma sequência própria da natureza narrativa, que conduz o leitor, provocando nele uma sensação de estar indo a algum lugar. Com as imagens produzidas tecnicamente, uma forma 
de composição ou leitura não-linear seria retomada. Ou seja, poderíamos passar a mensagem em primeiro lugar, para depois tentar decompô-la em interpretações.

Esses códigos bidimensionais, pertenceriam a uma sociedade telemática, cuja função real seria a produção de informação. De modo que:

Pode-se deixar a escrita, essa organização dos sinais, por conta das máquinas. O que se tem em mente aqui não são máquinas de escrever, no sentido tradicional dessa palavra, uma vez que, nesse caso, é ainda um ser humano que organiza em linhas, com um toque nas teclas, de acordo com as regras da escrita, os sinais gráficos distribuídos no teclado. Aqui temos em mente verdadeiras máquinas de escrever (inteligência artificial), que providenciam elas próprias essa organização. (FLUSSER, 2010, p. 25).

A partir de então, o filósofo identifica o código produzido pelas máquinas como uma outra escrita. “(...) os aparelhos não têm freios emocionais e não precisam respirar. Consequentemente podemos deixar o progresso e a ação histórica por conta dos aparelhos". (FLUSSER, 2010, p.45).

\section{A imagem pós-histórica - uma utopia imagética}

A chamada sociedade telemática, segundo Flusser, produz um novo tipo de imagem que, ao contrário das imagens pré-históricas, são produtos de textos e se alimentam deles. Para tentar diferenciar um mundo do futuro, da existência pré-histórica, o filósofo chama os novos tipos de imagens de "tecno-imagens", baseadas em uma "tecno-imaginação".

As "tecno-imagens" são entendidas por Flusser como produtos de um mundo mítico-mágico, em um sentido diferente do mito e da magia pré-histórica. Enquanto a imaginação pré-histórica tenta apreender o mundo, traduzindo o mundo, a imaginação pós-histórica tentaria ilustrar o texto, dotando o texto de signos.

A mudança para o chamado universo das imagens técnicas iria exigir um nível de criatividade desconhecido no passado, quando copiar a natureza era o objetivo de produção de imagens. Assim, a sociedade telemática, seria composta por pessoas mais livres e criativas.
Flusser aponta algumas direções, citando como exemplo a cibernética e a análise estrutural. O filósofo imagina o futuro da escrita, em tempos de tecno-imagens, "pensando em um transcodificador de textos, com inputs de textos e outputs de imagens", de maneira que "todos os textos seguiriam por essa caixa (notícias, eventos, artigos científicos, romance, poesia, especulações filosóficas), resultando em imagens (filmes, programas de TV, imagens fotográficas). Do ponto de vista do filósofo, a história fluiria por essa caixa e sairia dela sob forma de mito e magia, representando o tempo em sua totalidade. (FLUSSER, 2002, p.67).

Haveria, então, dois futuros possíveis: a escrita poderia se tornar uma crítica da tecno-imaginação, o que significaria o desmascaramento das ideologias que se escondem por trás do progresso técnico como autônomo das decisões humanas; ou numa segunda hipótese, a escrita serviria para a produção de pré-textos da tecno -imaginação, em um planejamento do progresso técnico, como o realizado pela escrita algorítmica. (FLUSSER, 2002, p.67-69).

Pensamento literal e imagético, ciência e arte, o que essas oposições conduzem e adequam, o que perdemos, questiona-se. Enquanto essa dicotomia prevalece, os numerais tomam de assalto a cena cultural. Apropriamos a inteligência artificial para criar e produzir uma arte digital, reflete o filósofo.

\section{Considerações - um pensamento dialógico}

O pensamento de Flusser parece dialogar com as análises de outros estudiosos que também exploram o campo da comunicação, tratando especificamente da escrita. Em uma primeira leitura, identificamos abordagem semelhante nos estudos desenvolvidos pelo teórico canadense Marshall McLuhan (1911-80).

Afirmando que a cultura escrita está sendo suplantada por uma cultura imagética e que o computador estaria substituindo funções humanas, como calcular, memorizar e escrever, Flusser parece concordar com McLuhan, ao anunciar uma era das imagens em A Galáxia de Gutenberg (1962). Também para McLuhan, o uso das tecnologias teria consequências sobre nossas percepções e hábitos, de maneira que estariam recriando processos mentais.

"Os efeitos da tecnologia não ocorrem nos níveis das opiniões e dos conceitos, eles se manifestam nas relações entre os sentidos e nas estruturas da percepção, num passo firme e sem qualquer resistência." (MCLUHAN, 2005, p.34). Nesse pensamento, descon- 
sidera-se a ação de diferentes grupos de interesse, que conduzem o uso de uma determinada tecnologia.

Entretanto, é entre Vilém Flusser e Walter Benjamin (1892-1940) que encontramos ainda mais confluências. Sabemos que ambos são judeus e viveram dias sob o domínio nazista. Em seus ensaios, além da influência de Kafka, a morte, a arte, o cinema, a fotografia e a escrita também são temas comuns. Ao afirmar que as imagens agora são em grande parte produzidas por softwares, "em laboratórios técnicos, sem a aura benjaminiana de transfiguração artística” (FLUSSER, 2010, p. 56), Flusser reverencia a teoria de Walter Benjamin.

De fato, esse é um aspecto importante, embora pontual no pensamento desse filósofo alemão, sobre as implicações da industrialização da cultura, apresentado no ensaio A obra de arte na era da sua reprodutibilidade técnica (1936). Membro da Escola de Frankfourt, Benjamin denuncia a apropriação da fotografia e do cinema para usos políticos e manipulação das massas, no que ele chamou de "a estetização da política", em sua teoria crítica.

Se Flusser fala do fim da escrita, vista como uma forma de comunicação anacrônica, antes dele, Benjamin denunciava o fim das narrativas, tratadas como uma forma de comunicação artesanal, diante da difusão dos romances.

Para Benjamin, o "primeiro indício do ocaso da narrativa é o surgimento do romance no início do período moderno". O segundo momento viria com o surgimento da imprensa, quando a valorização da informação representaria, também, o fim do romance. A figura do narrador é, então, substituída pela figura do escritor, de forma que "se a arte da narrativa é hoje rara, a difusão da informação tem uma participação decisiva nesse declínio.” (BENJAMIN, 2012, p.217-219).

Flusser parece explorar as ideias de Benjamin ao prever transformações mais próximas de seu tempo, como a mudança para o chamado universo das tecno -imagens inseridas na sociedade telemática, informacional. A tônica das transformações parece recair, tanto em um quanto em outro, sobre questões como criatividade e autenticidade e autoridade. (VAN DER MEULEN, 2010).

Diante dessa tensão permanente entre os limites da materialidade e os limites do humano, seguimos pautados por essa reflexão, em busca de pontes que nos levem a construções, análises identificadas com o novo tempo.

\section{Referências}

BENJAMIN, W. (1985) A obra de arte na era de sua reprodutibilidade técnica. In: Magia e Técnica, Arte e Politica. São Paulo: Brasiliense.

O narrador. Considerações sobre a obra de Nikolai Leskov. Magia e técnica, arte e política. In: Obras escolbidas. Vol. I. São Paulo: Brasiliense, 8ª .ed., 2012.

CARRIÈRE, Jean-Claude e ECO, Umberto. Não contem com o fim do livro. Rio de Janeiro: Editora Record, 2010.

CASTELLS, Manuel. A galáxia da Internet: reflexões sobre a Internet, os negócios e a sociedade. Rio de Janeiro: Jorge Zahar Editora, 2003.

DARTON, Robert. A questão do livro: passado, presente e futuro. São Paulo: Companhia das Letras, 2010.

FLUSSER, Vilém. The future of writing. In: Writings. Londres: University of Minnesota Press, 2002.

- A escrita - Há futuro para a escrita? São Paulo: Annablume, 2010.

- Los gestos: Fenomenologia y comunicacyón. Barcelona: Herder, 1994.

MCLUHAN, Marshall. A galáxia de Gutenberg, a formação do homem tipográfico. São Paulo, Editora Nacional, Editora da USP,1962.

- Os meios de comunicação como extensões do homem. Editora Cultrix, São Paulo: 2006.

VAN DER MEULEN, Sjoukje. Between Benjamin and McLuhan: Vilém Flusser's media theory. New German Critique, Ithaca (USA), no. 110, Vol. 37, p.180-207, 2010.

POSTER, Mark. An Introduction to Vilém Flusser's. In: Into the universe of technical images. Minneapolis: University of Minnesot Press, 2011.

Recebido em: 01/04/2015

Aprovado em: 25/05/2015 